OPEN ACCESS

Edited by:

Vincenzo Neri,

University of Foggia, Italy

Reviewed by:

Marcello Picchio,

Azienda Sanitaria Locale Roma 6, Italy

Jose M. Ramia,

Servicio de Salud de Castilla La

Mancha, Spain

${ }^{*}$ Correspondence:

Ming-Chang Tsa

tsaimc1110@gmail.com

†These authors have contributed equally to this work

Specialty section:

This article was submitted to

Visceral Surgery

a section of the journal

Frontiers in Surgery

Received: 01 December 2020

Accepted: 08 January 2021

Published: 15 February 2021

Citation:

Wang $C-C$, Tseng $M-H$, Wu S-W Yang $T-W$, Sung $W-W$, Wang $Y-T$,

Lee H-L, Shiu B-H, Lin C-C and

Tsai M-C (2021) The Role of Series

Cholecystectomy in High Risk Acute

Cholecystitis Patients Who Underwent

Gallbladder Drainage.

Front. Surg. 8:630916.

doi: 10.3389/fsurg.2021.630916

\section{The Role of Series Cholecystectomy in High Risk Acute Cholecystitis Patients Who Underwent Gallbladder Drainage}

\author{
Chi-Chih Wang ${ }^{1,2,3}$, Ming-Hseng Tseng ${ }^{4}$, Sheng-Wen Wu ${ }^{1,2,5}$, Tzu-Wei Yang ${ }^{1,2,3}$, \\ Wen-Wei Sung ${ }^{1,2,6}$, Yao-Tung Wang ${ }^{1,2,7}$, Hsiang-Lin Lee ${ }^{1,2,8}$, Bei-Hao Shiu ${ }^{1,2,8}$, \\ Chun-Che Lin $^{9,10+}$ and Ming-Chang Tsai ${ }^{1,2,3 * t}$
}

${ }^{1}$ Institute of Medicine, Chung Shan Medical University, Taichung, Taiwan, ${ }^{2}$ School of Medicine, Chung Shan Medical University, Taichung, Taiwan, ${ }^{3}$ Division of Gastroenterology and Hepatology, Chung Shan Medical University Hospital, Taichung, Taiwan, ${ }^{4}$ Department of Medical Informatics, Chung Shan Medical University, Taichung, Taiwan, ${ }^{5}$ Division of Nephrology, Chung Shan Medical University Hospital, Taichung, Taiwan, ${ }^{6}$ Department of Urology, Chung Shan Medical University Hospital, Taichung, Taiwan, ${ }^{7}$ Division of Pulmonary Medicine, Chung Shan Medical University Hospital, Taichung, Taiwan, ${ }^{8}$ Department of Surgery, Chung Shan Medical University Hospital, Taichung, Taiwan, ${ }^{9}$ Department of Internal Medicine, China Medical University Hospital, Taichung, Taiwan, ${ }^{10}$ School of Medicine, China Medical University, Taichung, Taiwan

Background: Cholecystectomy (CCY) is the only definitive therapy for acute cholecystitis. We conducted this study to evaluate which patients may not benefit from further CCY after percutaneous transhepatic gallbladder drainage (PTGBD) has been performed in acute cholecystitis patients.

Methods: Acute cholecystitis patients with PTGBD treatment were selected from one million random samples from the National Health Insurance Research Database obtained between January 2004 and December 2010. Recurrent biliary events (RBEs), RBE-related medical costs, RBE-related mortality rate and an RBE-free survival curve were compared in patients who accepted CCY within 2 months and patients without CCY within 2 months after the index admission.

Results: Three hundred and sixty-five acute cholecystitis patients underwent PTGBD at the index admission. A total of 190 patients underwent further CCY within 2 months after the index admission. The other 175 patients did not accept further CCY within 2 months after the index admission. RBE-free survival was significantly better in the CCY within 2 months group (60 vs. $42 \%, p<0.001$ ). The RBE-free survival of the CCY within 2 months group was similar to that of the no CCY within 2 months group in patients $\geq$ 80 years old and patients with a Charlson Comorbidity Index (CCI) score $\geq 9$.

Conclusions: We confirmed CCY after PTGBD reduced RBEs, RBE-related medical expenses, and the RBE-related mortality rate in patients with acute cholecystitis. In patients who accepted PTGBD, the RBE and survival benefits of subsequent CCY within 2 months became insignificant in patients $\geq 80$ years old or with a CCl score $\geq 9$.

Keywords: gallbladder drainage, cholecystectomy, acute cholecystitis, recurrent biliary event, medical expenses 


\section{INTRODUCTION}

Cholelithiasis is one of the most popular diseases with increasing prevalence and substantial burden on healthcare resources $(1,2)$. Because the abundant access to food worldwide increases the risk of obesity, the incidence rates of cholelithiasis grow accordingly $(3,4)$. Cholecystitis refers to inflammation of the gallbladder, and it can be defined as acute or chronic cholecystitis by the duration of the disease. Acute acalculous cholecystitis accounts for only $<10 \%(5,6)$ of all cholecystitis patients. Acute cholecystitis is a complication of gallstone disease and typically develops in patients with a history of symptomatic gallstones $(7,8)$.

After the diagnosis of acute cholecystitis, evaluations of the disease severity are necessary (9) to guide clinical management, such as early cholecystectomy (CCY) or percutaneous transhepatic gallbladder drainage (PTGBD), especially in critically ill patients $(10,11)$. According to the timing of CCY, CCY can be further classified as early or delayed CCY, and early CCY is a better choice than delayed CCY in terms of hospital stay and the medical expenses of treatment (12). Compared to delayed CCY, early CCY for cases within $72 \mathrm{~h}$ of symptom onset was associated with lower mortality rates and complication rates in the majority of cases in previous literature (12-14). Some references show that delayed CCY has a higher proportion of laparoscopy (15) and a lower complication rate (16). Although CCY is the only definitive therapy for acute cholecystitis $(9,17,18)$, there are patients who cannot tolerate or do not want surgical intervention despite the benefits of early or delayed CCY. Although the role of PTGBD in acute cholecystitis remains a debate $(19,20)$ compared to conservative treatment, PTGBD is useful for managing high surgical risk patients and patients with severe comorbidities $(9,21,22)$. Currently, there is no strong evidence to suggest surgery timing after patients with acute cholecystitis have undergone PTGBD (23-25), but CCY could decrease the likelihood of recurrent biliary events (RBEs) (26) after successful PTGBD intervention in these patients. As a result, patients with acute cholecystitis, who were successfully treated by PTGBD, should accept further early, interval, or delayed CCY to prevent future RBEs.

As our recognition, acute cholecystitis patients who have high comorbidity or were extremely old may not benefit from further CCY. We used the Charlson Comorbidity Index (CCI) $(27,28)$ to represent the level of comorbidities in patients in our study, which obtained from the Taiwan National Health Insurance Research Database (NHIRD). There are no current guidelines for the optimal timing for performing CCY after PTGBD, and only few real-world studies suggest the timing of CCY (29) due to surgical complications. We attempted to evaluate the benefits of CCY after patients with acute cholecystitis underwent PTGBD and whether the benefits disappear due to severe comorbidities or old age in a retrospective database cohort study.

\section{METHODS}

Our study was approved by the Institutional Review Board (IRB) of Chung Shan Medical University Hospital in Taiwan. All methods were performed in accordance with the relevant regulations and under the surveillance of the IRB of Chung Shan Medical University Hospital.

\section{Study Design}

This study was a population-based retrospective cohort study based on Taiwan's NHIRD, which covers more than $99 \%$ of the entire population (30). The NHIRD has been described in detail in previous studies (31-33).

Cholelithiasis cases were selected from one million random samples from the NHIRD between 2004 and 2011 using the codes of International Statistical Classification of Diseases and Related Health Problems, 9th Edition (ICD-9) recorded by emergency room (ER) visits or admissions. Patients with acute cholecystitis were selected using ICD-9 codes documented in 2004-2010 to ensure the follow-up period is more than 1 year, and then, we identified patients who underwent PTGBD (procedure code 33106B) during an index admission or during an ER course 3 days before admission. Patients who had previously undergone CCY or PTGBD between the index admission and 2004 were excluded. The observation period was selected from the index admission to December 2011 or the expired date of patients. A total of 365 patients with acute cholecystitis who underwent PTGBD were selected, and 190 of these patients accepted CCY within 2 months (60 days) after the index admission. The other 175 patients with acute cholecystitis who underwent PTGBD during the index admission did not accept CCY 2 months after the index admission. Twenty-five patients in the no CCY within 2 months group eventually underwent CCY during the follow-up period. We compared age, gender, baseline CCI score, the proportion of laparoscopic and open CCY procedures, the total follow-up time, time to events, RBEs, overall mortality, RBE-related mortality, and the total medical expenses for RBEs between these two groups. RBE-related mortality was defined as mortality events due to RBEs during hospitalization or within 5 days after discharge. The design of this study is shown in Figure 1.

An economic analysis of the costs of the index admission, CCY events, ER visits and hospitalization due to RBEs, and the total medical expenses were compared between the CCY within 2 months group and the no CCY within 2 months group for patients with acute cholecystitis who initially underwent PTGBD under Taiwan's national health insurance system.

\section{Data Processing and Statistical Analysis}

The one million individuals who represent the nationwide population between 2004 and 2011 in Taiwan were processed using Microsoft SQL Server 2008 R2 (Microsoft Corporation, Redmond, WA, USA) with the SQL programming language. Statistical analysis was performed using OpenEpi: Open Source Epidemiologic Statistics for Public Health, version 3.01 (40). Kaplan-Meier survival analyses were conducted using SPSS version 19.

The data obtained from the study were processed using ChiSquare $\left(\chi^{2}\right)$ tests for categorical variables, one-way analyses of variance (ANOVA) for continuous variables, and log-rank (Mantel-Cox) tests for disease-free survival curves. A two-tailed $P$-value of 0.05 was considered statistically significant. 


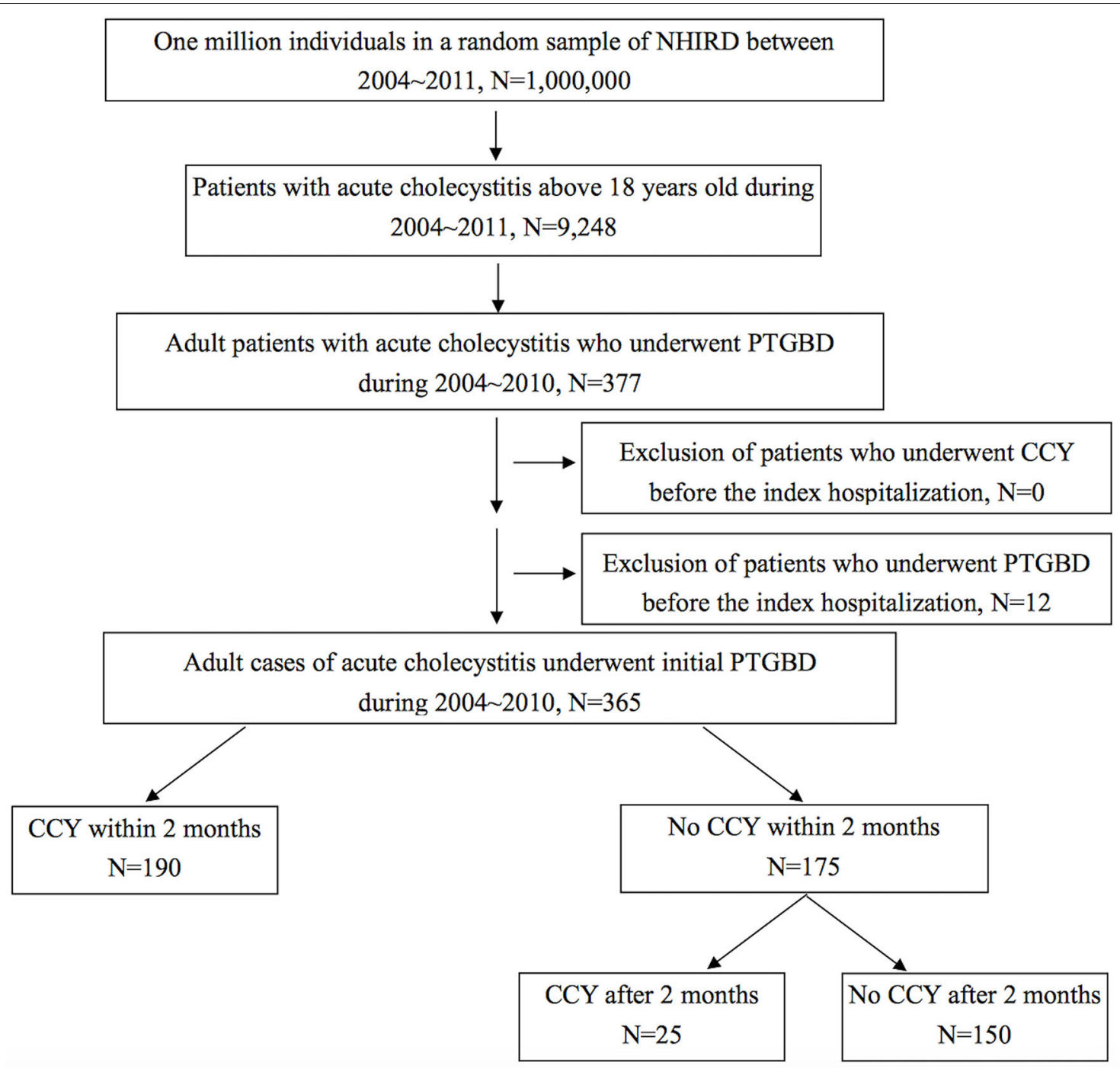

FIGURE 1 | Flow chart for case selection from a database of one million nationwide representatives in Taiwan. NHIRD, National Health Insurance Research Database; PTGBD, percutaneous transhepatic gallbladder drainage; CCY, cholecystectomy.

\section{RESULTS}

A total 9,248 adult patients with acute cholecystitis were selected from one million samples from January 2004 to December 2011. Because the follow-up period should be at least 1 year, we included 377 acute cholecystitis patients who underwent PTGBD between January 2004 and December 2010. Twelve patients were excluded because of previous PTGBD before the index admission. The data for 365 acute cholecystitis patients who underwent PTGBD at the index admission were collected. A total of 190 patients with a mean age of $68.42 \pm 13.17$ years underwent further CCY within 2 months after the index admission. The other 175 patients, with a mean age of $72.67 \pm 13.75$ years, did not accept further CCY within 2 months after the index admission. The baseline CCI score, $5.77 \pm 3.41$ in the CCY within 2 months group and $7.79 \pm 4.10$ in the no CCY within 2 months group, was significantly higher in the no CCY group $(p=0.01)$. As for the components of the CCI, the proportions of patients with congestive heart failure ( 10.53 vs. $25.14 \%, p<0.01)$, hemiplegia or paraplegia ( 0 vs. $3.43 \%, p=0.04$ ), and chronic kidney disease ( 9.47 vs. $25.14 \%, p<0.01$ ) were significantly higher in the no CCY group. The total follow-up duration was significantly longer in the CCY within 2 months group than in the no CCY within 2 months group (39.68 \pm 23.47 vs. $23.47 \pm 20.26, p=0.047)$. The detailed baseline demographic data are shown in Table $\mathbf{1 .}$

Reflecting the culture in Taiwan, surgical intervention is the last choice for treatment. In our analysis, only 190 (52.05\%) of the 365 patients underwent CCY within 60 days after previous PTGBD during index admission for acute cholecystitis. In addition, 25 patients eventually accepted CCY during follow-up, and $15(60 \%)$ of these patients underwent laparoscopic CCY. The overall mortality rate was $19.47 \%$ in the CCY within 2 months 
TABLE 1 | Demographic data of patients underwent percutaneous transhepatic gallbladder drainage.

\begin{tabular}{|c|c|c|c|c|c|}
\hline \multirow[t]{2}{*}{ Study group } & \multicolumn{2}{|c|}{$\begin{array}{c}\text { CCY within } 2 \\
\text { months } N=190\end{array}$} & \multicolumn{2}{|c|}{$\begin{array}{l}\text { No CCY within } 2 \\
\text { months } N=175\end{array}$} & \multirow[t]{2}{*}{$P$-value } \\
\hline & $N$; Mean & $S D ; \%$ & $N$; Mean & $S D ; \%$ & \\
\hline Age (SD) & 68.42 & 13.17 & 72.67 & 13.75 & 0.57 \\
\hline Gender & & & & & 0.20 \\
\hline Male & 117 & 61.58 & 96 & 54.86 & \\
\hline Female & 73 & 38.42 & 79 & 45.14 & \\
\hline $\begin{array}{l}\text { Follow up time } \\
\text { (months) }\end{array}$ & 39.68 & 23.47 & 23.47 & 20.26 & 0.047 \\
\hline Comorbidity & 5.77 & 3.41 & 7.79 & 4.10 & 0.01 \\
\hline \multicolumn{6}{|l|}{$\mathrm{CCl}$ score (SD) } \\
\hline $\mathrm{Ml}$ & 7 & 3.68 & 13 & 7.43 & 0.29 \\
\hline $\mathrm{CHF}$ & 20 & 10.53 & 44 & 25.14 & $<0.01$ \\
\hline $\begin{array}{l}\text { Peripheral vascular } \\
\text { disease }\end{array}$ & 12 & 6.32 & 18 & 10.29 & 0.38 \\
\hline CVA & 38 & 20.00 & 55 & 31.43 & 0.43 \\
\hline Dementia & 22 & 11.58 & 28 & 16.00 & 0.47 \\
\hline CPD & 64 & 33.68 & 70 & 40.00 & 0.45 \\
\hline Rheumatologic disease & 6 & 3.16 & 4 & 2.29 & 0.88 \\
\hline PUD & 101 & 53.16 & 90 & 51.43 & 0.95 \\
\hline Mild liver disease & 40 & 21.05 & 41 & 23.43 & 0.86 \\
\hline DM & 71 & 37.37 & 85 & 48.57 & 0.10 \\
\hline DM with complication & 19 & 10.00 & 27 & 15.43 & 0.29 \\
\hline $\begin{array}{l}\text { Hemiplegia or } \\
\text { paraplegia }\end{array}$ & 0 & 0.00 & 6 & 3.43 & 0.04 \\
\hline CKD & 18 & 9.47 & 44 & 25.14 & $<0.01$ \\
\hline $\begin{array}{l}\text { Malignancy (including } \\
\text { leukemia and } \\
\text { lymphoma) }\end{array}$ & 31 & 16.32 & 38 & 21.71 & 0.42 \\
\hline Liver cirrhosis & 6 & 3.16 & 13 & 7.43 & 0.18 \\
\hline Metastatic solid tumor & 10 & 5.26 & 19 & 10.86 & 0.14 \\
\hline HIV & 0 & - & 0 & - & N.A. \\
\hline
\end{tabular}

SD, standard deviation; CCl score, Charlson Comorbidity Index score; MI, Myocardial infarction; CHF, congestive heart failure; CVA, Cerebrovascular accident; PUD, Peptic ulcer disease; CPD, Chronic pulmonary disease; DM, Diabetes; CKD, chronic kidney disease; HIV, human immunodeficiency virus; N.A., not applicable.

group and $50.29 \%$ in the no CCY within 2 months group, in which the patients had higher CCI scores and older age. In terms of RBE-related mortality, five patients died in the no CCY within 2 months group, while no patients died in the CCY within 2 months group. Therefore, the CCY within 2 months group had a better survival probability in our analysis. All the details were shown in Table 2.

\section{RBEs}

The definition of RBE included ER visits and admissions due to cholelithiasis, cholecystitis, cholangitis, and biliary pancreatitis. Although the time to the event was shorter in the subsequent CCY within 2 months group (9.6 \pm 15.18 months) than in the no CCY within 2 months group (11.21 \pm 13.92 months), the total number of RBEs was higher in the no CCY within 2 months group. The total number of RBEs was 111 events
TABLE 2 | Outcomes comparisons between patients of acute cholecystitis underwent CCY within 2 months/ No CCY within 2 months after gallbladder drainage.

\begin{tabular}{|c|c|c|c|c|c|}
\hline \multirow[t]{2}{*}{ Study group } & \multicolumn{2}{|c|}{$\begin{array}{c}\text { CCY within } 2 \\
\text { months } N=190\end{array}$} & \multicolumn{2}{|c|}{$\begin{array}{l}\text { No CCY within } 2 \\
\text { months } N=175\end{array}$} & \multirow[t]{2}{*}{$P$-value } \\
\hline & $N$ & $S D ; \%$ & $N$ & $S D ; \%$ & \\
\hline Age (SD) & 68.42 & 13.17 & 72.67 & 13.75 & 0.568 \\
\hline $\begin{array}{l}\text { Surgical method } \\
\text { Open CCY }\end{array}$ & 102 & 53.68 & 10 & 5.71 & N.A. \\
\hline Laparoscopic CCY & 88 & 46.32 & 15 & 8.57 & N.A. \\
\hline $\begin{array}{l}\text { Time to events } \\
\text { (months) }\end{array}$ & 9.60 & 15.18 & 11.21 & 13.92 & 0.246 \\
\hline \multicolumn{6}{|l|}{ RBE } \\
\hline Patients & 59 & 31.05 & 81 & 46.29 & 0.003 \\
\hline Events & 111 & N.A. & 173 & N.A. & \\
\hline Overall mortality & 37 & 19.47 & 88 & 50.29 & $<0.001$ \\
\hline RBE related mortality & 0 & 0.00 & 5 & 2.86 & 0.025 \\
\hline $\begin{array}{l}\text { Total RBE medical } \\
\text { expenses (NT \$) }\end{array}$ & 68,561 & 85,343 & 120,284 & 151,225 & $<0.001$ \\
\hline
\end{tabular}

$S D$, standard deviation; CCY, cholecystectomy; RBE, recurrent biliary event; NT \$, New Taiwan dollars; N.A., not applicable.

in 59 patients in the CCY within 2 months group and 173 RBEs in 81 patients in the no CCY within 2 months group, which showed more RBEs in the no CCY within 2 months group. This situation resulted in the total medical expenses for RBEs being much higher in the no CCY within 2 months group $(68,561 \pm 85,343 \mathrm{NT} \$$ vs. $120,284 \pm 151,225 \mathrm{NT} \$)$. The comparisons of medical expenses were demonstrated in Table 3.

\section{RBE-Free Survival}

To evaluate the safety and protective effects of CCY after PTGBD for acute cholecystitis, we examined the RBE-free survival, which referred to both RBEs or mortality events as end points for measurements. RBE-free survival was significantly better in the CCY within 2 months group than in the no CCY within 2 months group (60 vs. $42 \%, p<0.001)$. The results are shown in Figure 2. After we stratified the CCY within 2 months group patients by age and CCI score, the RBE-free survival became similar to that of the no CCY within 2 months group patients when patients were older than 80 years old (56 vs. $42 \%, p=0.421$ ) or had a CCI score $\geq 9$ (54 vs. $42 \%, p=0.425$ ). Detailed information is provided in Figure 3.

\section{Medical Expenses}

Medical expenses for the index admission, CCY, and subsequent admissions and ER visits due to RBEs and the total medical charges were calculated. We isolated the 25 patients who eventually accepted CCY at least 2 months apart from the index admission from patients without CCY within 2 months.

The average medical expenses for the index admission were 89,951 NT\$, 53,866 NT\$, and 188,212 NT\$ in the CCY within 2 months group, CCY after 2 months group, and no CCY 
TABLE 3 | The comparisons of medical expenses between patients underwent PTGBD accept CCY within/after 2 months or without CCY.

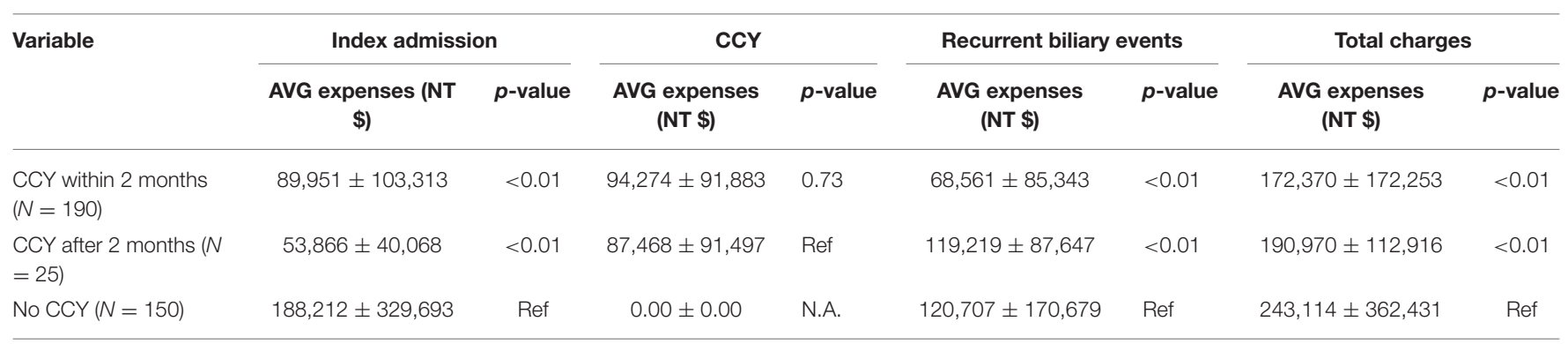

PTGBD, percutaneous transhepatic gallbladder drainage; CCY, cholecystectomy; NT \$, New Taiwan dollars; AVG, average; ref, reference; N.A., not applicable.

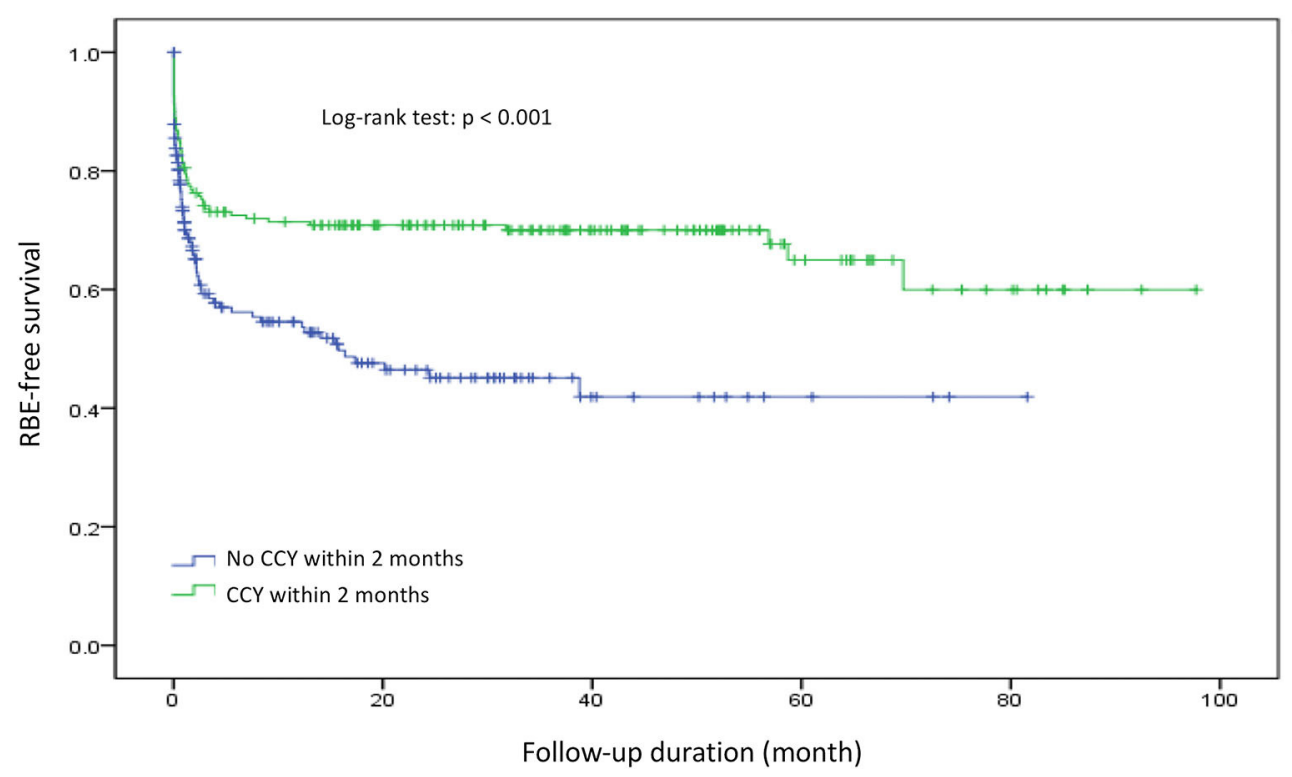

FIGURE 2 | Recurrent biliary event survival comparison between the CCY within 2 months group and the no CCY within 2 months group. RBE, recurrent biliary event.

group, respectively. The much higher medical expenses in the no CCY group indicated the complicated clinical condition and significant comorbidities in this group of patients. For the medical expenses of RBEs, the average expenses were 120,707 NT\$ in the no CCY group, which was much higher than the 68,561 NT\$ in the CCY within 2 months group.

The average total medical costs were 243,114 NT\$, 190,970 NT\$, and $172,370 \mathrm{NT} \$$ in the no CCY group, CCY after 2 months group, and CCY within 2 months group $(p<0.01$ ), which suggests the later CCY was performed, the higher the medical expenses were. The medical cost comparisons are shown in Table 3.

\section{DISCUSSION}

Reflecting the culture in Taiwan, surgical intervention was always the last choice for treatment. In our analysis, only $190(52.05 \%)$ of the 365 patients underwent CCY within 60 days after previous PTGBD during the index admission for acute cholecystitis. Although previous studies showed that CCI score and the American Society of Anesthesiologists physical status classification (ASA-PS) can be used for surgical risk classification (34) in acute cholecystitis evaluation $(35,36)$, some reports showed similar survival benefits and lower complication rates using laparoscopic CCY compared to initial PTGBD in high risk acute cholecystitis patients (37). No adequate risk evaluation has ever been explored in second stage CCY after PTGBD.

In our study, the data were collected for patients who underwent PTGBD for high risk acute cholecystitis (from a retrospective database that included a random selection of $\sim 5 \%$ of the Taiwan population), and only $4.08 \%$ of patients underwent PTGBD instead of CCY for acute cholecystitis treatment at the index admission. This observation indicates that CCY is the favored treatment method for acute cholecystitis in Taiwan and compatible with the guideline suggestion worldwide.

According to other investigations into RBEs after patients accepted PTGBD without further CCY, the cumulative incidence of biliary events was $\sim 30 \%$ (38). In our analysis, the proportion of patients who experienced RBEs was $31.05 \%$ in the CCY within 2 months group and $46.29 \%$ in the no CCY within 2 months group. Our RBE rate is higher than that of other 

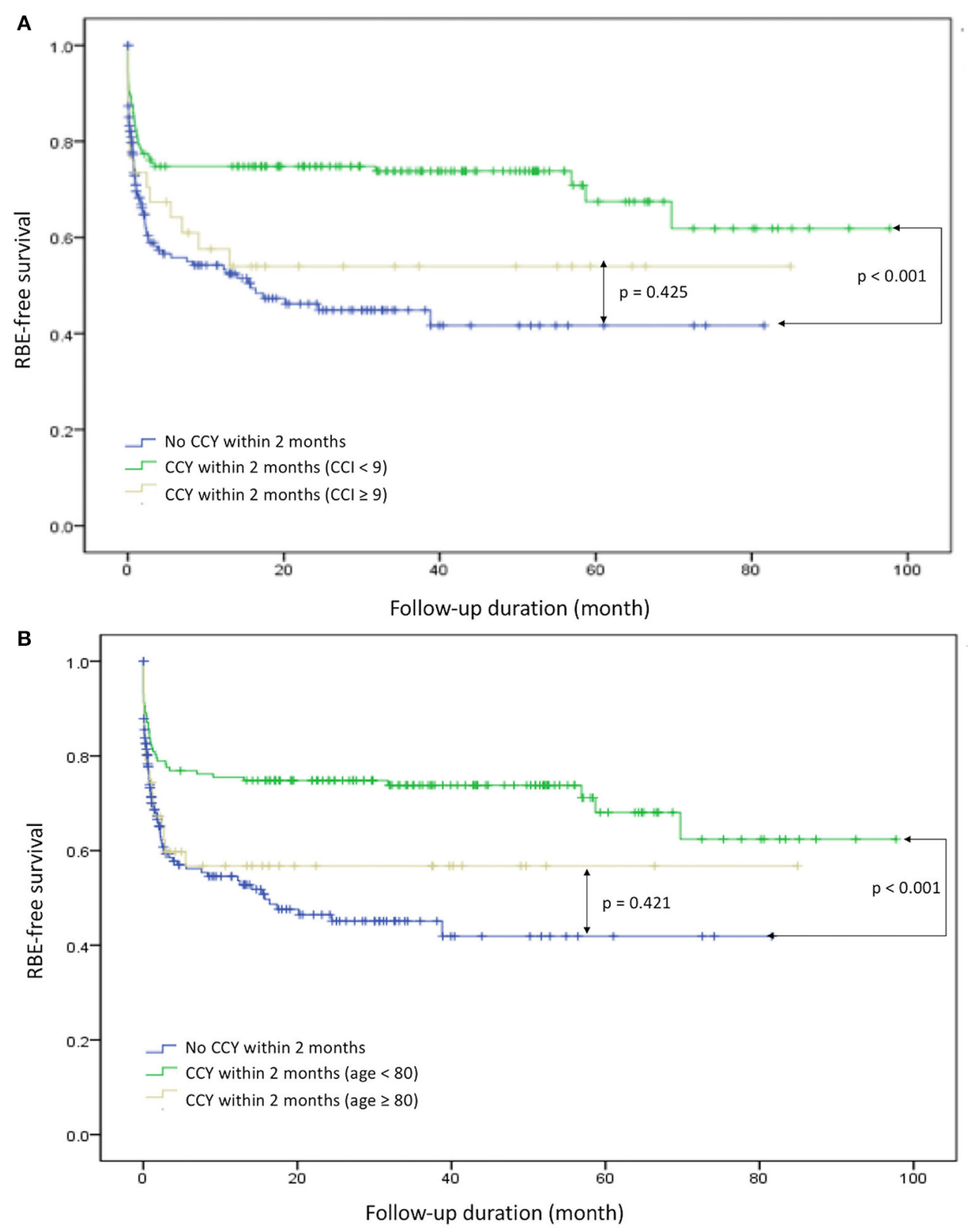

FIGURE 3 | Recurrent biliary event survival comparison in specific groups. (A) $\mathrm{CCl} \geq 9$ and $\mathrm{CCY}<9$ with CCY within 2 months and no CCY within 2 months. (B) Age $\geq 80$ and age $<80$ with CCY within 2 months and no CCY within 2 months. RBE, recurrent biliary event; CCl, Charlson Comorbidity Index; CCY, cholecystectomy.

analyses because not all of our patients accepted CCY within 2 months as a series treatment algorithm; some of them underwent CCY due to RBEs in a short time period after the index admission. Another reason is the follow-up duration was significantly longer in the CCY within 2 months group than in the no CCY within 2 months group (39.68 vs. 20.26 months, $p=0.047$ ), which led to higher RBEs in comparison. Even in this setting, the RBEs, RBE-related medical expenses, and RBE-related mortality rate were significantly lower in the $\mathrm{CCY}$ within 2 months group. This finding confirmed that CCY can reduce RBEs after PTGBD treatment in high risk acute cholecystitis patients.

\section{RBE-Free Survival}

Due to improvements in technology, equipment, and surgical skills, CCY, either early CCY or delayed CCY, are the standard treatment of choice in acute cholecystitis. We focused on which patients may not benefit from the current aggressive treatment methods for acute cholecystitis. A large scaled study have been shown elderly is not a problem for CCY (39), but the definition 
of elderly is too young for modern society in our opinion. As we further evaluated the RBE-free survival in the CCY within 2 months group using age $\geq 65$ vs. age $<65$, age $\geq 75$ vs. age $<75$, age $\geq 80$ vs. age $<80$, CCI score $\geq 6$ vs. CCI score $<6$, CCI score $\geq 7$ vs. CCI score $<7$, CCI score $\geq 8$ vs. CCI score $<8$, and CCI score $\geq 9$ vs. CCI score $<9$, we found that when patients were older than 80 years or their CCI score exceeded nine, the benefits of RBE-free survival became insignificant in the CCY within 2 months group.

\section{Medical Expenses}

The financial impact was considered, and the patients who initially underwent PTGBD without further CCY had the highest medical costs, while the patients who initially underwent PTGBD and accepted CCY within or after 2 months from the index admission had similar total medical costs. Whether patients eventually underwent CCY or not, the medical expenses due to RBEs were higher in the no CCY within 2 months group than in the CCY within 2 months group. Earlier CCY after PTGBD decreased medical expenses.

There are limitations to our study. For example, comorbidities associated with retrospective database analysis-related selection bias may confound the assignment to CCY. This selection resulted in patients of younger age with less comorbidities and conceivably better performance status in the CCY within 2 months group than in the no CCY within 2 months group. This bias makes our results more reliable if the subgroup analysis showed no benefits over patients in the CCY within 2 months group than in the no CCY within 2 months group, because patients with better conditions in the same CCI score are suggested to accept CCY clinically. Another limitation is that we could not determine if the patients accepted CCY within 2 months as a series treatment algorithm after PTGBD or just accepted CCY at another cholecystitis event within 2 months because of the limitations of the NHIRD. Because whether high risk acute cholecystitis patients who undergo PTGBD accept series CCY depends on personal choices, further prospective randomized studies are not a possible solution because this limitation would be present in similar studies. Future prospective multi-center studies can clarify and avoid the selection bias in different study groups.

\section{REFERENCES}

1. Peery AF, Crockett SD, Barritt AS, Dellon ES, Eluri S, Gangarosa LM, et al. Burden of gastrointestinal, liver, and pancreatic diseases in the United States. Gastroenterology. (2015) 149:1731-41 e1733. doi: 10.1053/j.gastro.2015.08.045

2. Peery AF, Crockett SD, Murphy CC, Lund JL, Dellon ES, Williams JL, et al. Burden and cost of gastrointestinal, liver, and pancreatic diseases in the United States: update 2018. Gastroenterology. (2019) 156:254-72 e211. doi: 10.1053/j.gastro.2018.08.063

3. Shaffer EA. Epidemiology and risk factors for gallstone disease: has the paradigm changed in the twenty-first century? Curr Gastroenterol Rep. (2005) 7:132-40. doi: 10.1007/s11894-005-0051-8

4. Shaffer EA. Gallstone disease: epidemiology of gallbladder stone disease. Best Pract Res Clin Gastroenterol. (2006) 20:981-96. doi: 10.1016/j.bpg.2006.05.004

\section{CONCLUSIONS}

We confirmed CCY after PTGBD can reduce RBEs, RBE-related medical expenses, and the RBE-related mortality rate in high surgical risk patients with acute cholecystitis. In patients who underwent PTGBD, the RBE and survival benefits of subsequent CCY within 2 months became insignificant in patients older or equal than 80 years old or with a CCI score $\geq 9$.

\section{DATA AVAILABILITY STATEMENT}

The raw data supporting the conclusions of this article will be made available by the authors, without undue reservation.

\section{ETHICS STATEMENT}

The studies involving human participants were reviewed and approved by IRB of Chung Shan Medical University Hospital. Written informed consent for participation was not required for this study in accordance with the national legislation and the institutional requirements.

\section{AUTHOR CONTRIBUTIONS}

C-CL and M-CT: designed and carry out this study. C-CW, C-CL, and M-CT: conception and design. M-HT, S-WW, and T-WY: acquisition of data. C-CW, S-WW, and W-WS: analysis and interpretation of data. C-CW and Y-TW: drafting of the manuscript. H-LL and B-HS: critical revision of the manuscript. W-WS and M-HT: statistical analysis. M-HT, C-CL, and M-CT: supervision. All authors reviewed the manuscript.

\section{FUNDING}

This work was supported by grants from Chung Shan Medical University Hospital research program (CSH-2013-C-032; CSH2021-C-006).

\section{ACKNOWLEDGMENTS}

Thanks for the assistance from Hsuan-Yi Chen, Chang-Cheng Su, Shih-Ming Huang, and Wei-Liang Chen for the trivial details.

5. Shapiro MJ, Luchtefeld WB, Kurzweil S, Kaminski DL, Durham RM, Mazuski JE. Acute acalculous cholecystitis in the critically ill. Am Surg. (1994) 60:335-9.

6. Huffman JL, Schenker S. Acute acalculous cholecystitis: a review. Clin Gastroenterol Hepatol. (2010) 8:15-22. doi: 10.1016/j.cgh.2009.08.034

7. Friedman GD. Natural history of asymptomatic and symptomatic gallstones. Am J Surg. (1993) 165:399-404. doi: 10.1016/S0002-9610(05)80930-4

8. Shabanzadeh DM. Incidence of gallstone disease and complications. Curr Opin Gastroenterol. (2018) 34:81-9. doi: 10.1097/MOG.0000000000000418

9. Yokoe M, Hata J, Takada T, Strasberg SM, Asbun HJ, Wakabayashi G, et al. Tokyo guidelines 2018: diagnostic criteria and severity grading of acute cholecystitis (with videos). J Hepatobiliary Pancreat Sci. (2018) 25:4154. doi: 10.1002/jhbp. 515

10. Ito K, Fujita N, Noda Y, Kobayashi G, Kimura K, Sugawara T, et al. Percutaneous cholecystostomy versus gallbladder aspiration for acute 
cholecystitis: a prospective randomized controlled trial. AJR Am J Roentgenol. (2004) 183:193-6. doi: 10.2214/ajr.183.1.1830193

11. Gomi H, Solomkin JS, Schlossberg D, Okamoto K, Takada T, Strasberg SM, et al. Tokyo guidelines 2018: antimicrobial therapy for acute cholangitis and cholecystitis. J Hepatobiliary Pancreat Sci. (2018) 25:316. doi: $10.1002 /$ jhbp. 518

12. Okamoto K, Suzuki K, Takada T, Strasberg SM, Asbun HJ, Endo I, et al. Tokyo guidelines 2018: flowchart for the management of acute cholecystitis. $J$ Hepatobiliary Pancreat Sci. (2018) 25:55-72. doi: 10.1002/jhbp.516

13. Chandler CF, Lane JS, Ferguson P, Thompson JE, Ashley SW. Prospective evaluation of early versus delayed laparoscopic cholecystectomy for treatment of acute cholecystitis. Am Surg. (2000) 66:896-900.

14. Gutt CN, Encke J, Koninger J, Harnoss JC, Weigand K, Kipfmuller K, et al. Acute cholecystitis: early versus delayed cholecystectomy, a multicenter randomized trial (ACDC study, NCT00447304). Ann Surg. (2013) 258:38593. doi: 10.1097/SLA.0b013e3182a1599b

15. Wang CC, Tsai MC, Wang YT, Yang TW, Chen HY, Sung WW, et al. Role of cholecystectomy in choledocholithiasis patients underwent endoscopic retrograde cholangiopancreatography. Sci Rep. (2019) 9:2168. doi: 10.1038/s41598-018-38428-z

16. Ozkardes AB, Tokac M, Dumlu EG, Bozkurt B, Ciftci AB, Yetisir F, et al. Early versus delayed laparoscopic cholecystectomy for acute cholecystitis: a prospective, randomized study. Int Surg. (2014) 99:56-61. doi: 10.9738/INTSURG-D-13-00068.1

17. Ansaloni L, Pisano M, Coccolini F, Peitzmann AB, Fingerhut A, Catena F, et al. 2016 WSES guidelines on acute calculous cholecystitis. World J Emerg Surg. (2016) 11:25. doi: 10.1186/s13017-016-0088-Z

18. Bagla P, Sarria JC, Riall TS. Management of acute cholecystitis. Curr Opin Infect Dis. (2016) 29:508-13. doi: 10.1097/QCO.0000000000 000297

19. Hatzidakis AA, Prassopoulos P, Petinarakis I, Sanidas E, Chrysos E, Chalkiadakis G, et al. Acute cholecystitis in high-risk patients: percutaneous cholecystostomy vs conservative treatment. Eur Radiol. (2002) 12:177884. doi: 10.1007/s00330-001-1247-4

20. Barak O, Elazary R, Appelbaum L, Rivkind A, Almogy G. Conservative treatment for acute cholecystitis: clinical and radiographic predictors of failure. Isr Med Assoc J. (2009) 11:739-43.

21. Kortram K, De Vries Reilingh TS, Wiezer MJ, Van Ramshorst B, Boerma D. Percutaneous drainage for acute calculous cholecystitis. Surg Endosc. (2011) 25:3642-6. doi: 10.1007/s00464-011-1771-5

22. Viste A, Jensen D, Angelsen JH, Hoem D. Percutaneous cholecystostomy in acute cholecystitis; a retrospective analysis of a large series of 104 patients. BMC Surg. (2015) 15:17. doi: 10.1186/s12893-015-0002-8

23. Choi JW, Park SH, Choi SY, Kim HS, Kim TH. Comparison of clinical result between early laparoscopic cholecystectomy and delayed laparoscopic cholecystectomy after percutaneous transhepatic gallbladder drainage for patients with complicated acute cholecystitis. Korean J Hepatobiliary Pancreat Surg. (2012) 16:147-53. doi: 10.14701/kjhbps.2012.16.4.147

24. Han IW, Jang JY, Kang MJ, Lee KB, Lee SE, Kim SW. Early versus delayed laparoscopic cholecystectomy after percutaneous transhepatic gallbladder drainage. J Hepatobiliary Pancreat Sci. (2012) 19:187-93. doi: 10.1007/s00534-011-0458-6

25. Jung WH, Park DE. Timing of cholecystectomy after percutaneous cholecystostomy for acute cholecystitis. Korean J Gastroenterol. (2015) 66:209-14. doi: 10.4166/kjg.2015.66.4.209

26. Alvino DML, Fong ZV, Mccarthy CJ, Velmahos G, Lillemoe KD, Mueller $\mathrm{PR}$, et al. Long-term outcomes following percutaneous cholecystostomy tube placement for treatment of acute calculous cholecystitis. J Gastrointest Surg. (2017) 21:761-9. doi: 10.1007/s11605-017-3375-4

27. Charlson ME, Pompei P, Ales KL, Mackenzie CR. A new method of classifying prognostic comorbidity in longitudinal studies: development and validation. $J$ Chronic Dis. (1987) 40:373-83. doi: 10.1016/0021-9681(87)90171-8
28. Quan H, Sundararajan V, Halfon P, Fong A, Burnand B, Luthi JC, et al. Coding algorithms for defining comorbidities in ICD-9-CM and ICD-10 administrative data. Med Care. (2005) 43:1130-9. doi: 10.1097/01.mlr.0000182534.19832.83

29. Inoue $\mathrm{K}$, Ueno $\mathrm{T}$, Nishina $\mathrm{O}$, Douchi $\mathrm{D}$, Shima $\mathrm{K}$, Goto $\mathrm{S}$, et al. Optimal timing of cholecystectomy after percutaneous gallbladder drainage for severe cholecystitis. BMC Gastroenterol. (2017) 17:71. doi: $10.1186 /$ s12876-017-0631-8

30. Cheng TM. Taiwan's new national health insurance program: genesis and experience so far. Health Aff. (2003) 22:61-76. doi: 10.1377/hlthaff.22.3.61

31. $\mathrm{Wu} \mathrm{CY}$, Kuo KN, Wu MS, Chen YJ, Wang CB, Lin JT. Early Helicobacter pylori eradication decreases risk of gastric cancer in patients with peptic ulcer disease. Gastroenterology. (2009) 137:1641-8 e16412. doi: 10.1053 /j.gastro.2009.07.060

32. Wu CY, Chan FK, Wu MS, Kuo KN, Wang CB, Tsao CR, et al. Histamine2-receptor antagonists are an alternative to proton pump inhibitor in patients receiving clopidogrel. Gastroenterology. (2010) 139:116571. doi: $10.1053 /$ j.gastro. 2010.06 .067

33. Wang CC, Tsai MC, Sung WW, Yang TW, Chen HY, Wang YT, et al. Risk of cholangiocarcinoma in patients undergoing therapeutic endoscopic retrograde cholangiopancreatography or cholecystectomy: a population based study. World J Gastrointest Oncol. (2019) 11:23849. doi: 10.4251/wjgo.v11.i3.238

34. Hocevar LA, Fitzgerald BM. American Society of Anesthesiologists Staging. Treasure Island, FL: StatPearls (2019).

35. Iwashita Y, Ohyama T, Honda G, Hibi T, Yoshida M, Miura F, et al. What are the appropriate indicators of surgical difficulty during laparoscopic cholecystectomy? Results from a Japan-Korea-Taiwan multinational survey. J Hepatobiliary Pancreat Sci. (2016) 23:533-47. doi: 10.1002/ jhbp. 375

36. Iwashita Y, Hibi T, Ohyama T, Honda G, Yoshida M, Miura F, et al. An opportunity in difficulty: Japan-Korea-Taiwan expert Delphi consensus on surgical difficulty during laparoscopic cholecystectomy. J Hepatobiliary Pancreat Sci. (2017) 24:191-8. doi: 10.1002/jhbp.440

37. Loozen CS, Van Santvoort HC, Van Duijvendijk P, Besselink MG, Gouma DJ, Nieuwenhuijzen GA, et al. Laparoscopic cholecystectomy versus percutaneous catheter drainage for acute cholecystitis in high risk patients (CHOCOLATE): multicentre randomised clinical trial. BMJ. (2018) 363:k3965. doi: 10.1136/bmj.k3965

38. Hung YL, Chong SW, Cheng CT, Liao CH, Fu CY, Hsieh $\mathrm{CH}$, et al. Natural course of acute cholecystitis in patients treated with percutaneous transhepatic gallbladder drainage without elective cholecystectomy. J Gastrointest Surg. (2019) 24:772-9. doi: 10.1007/s11605-01904213-0

39. Nassar Y, Richter S. Management of complicated gallstones in the elderly: comparing surgical and non-surgical treatment options. Gastroenterol Rep. (2019) 7:205-11. doi: 10.1093/gastro/goy046

40. Dean Ag SK, Soe Mm. OpenEpi: Open Source Epidemiologic Statistics for Public Health, Version. (2013). Available online at: www.OpenEpi.com (accessed 01 June, 2018).

Conflict of Interest: The authors declare that the research was conducted in the absence of any commercial or financial relationships that could be construed as a potential conflict of interest.

Copyright (๑ 2021 Wang, Tseng, Wu, Yang, Sung, Wang, Lee, Shiu, Lin and Tsai. This is an open-access article distributed under the terms of the Creative Commons Attribution License (CC BY). The use, distribution or reproduction in other forums is permitted, provided the original author(s) and the copyright owner $(s)$ are credited and that the original publication in this journal is cited, in accordance with accepted academic practice. No use, distribution or reproduction is permitted which does not comply with these terms. 